\title{
PENGARUH PENINGKATAN BERAT BADAN SELAMA KEHAMILAN TERHADAP BERAT BADAN BAYI YANG BARU LAHIR DI KLINIK BIDAN K.SARAGIH KECAMATAN PORSEA
}

\author{
Rina Marlina Manalu \\ Program Studi D-III Keperawatan, STIKes Arjuna \\ E-mail : manaluurina23@gmail.com
}

\begin{abstract}
Research has been carried out at the Clinic Midwife K. Saragih in 2019 to identify the effect of increasing body weight during pregnancy on birth weight. The research design used was descriptive correlation with a sample size of 100 people with a total sampling method. The instrument in this study was secondary data obtained from the midwife's clinic K.Saragih, KMS for pregnant women, birth records, and birth weight of babies. From the research results, it was obtained that the average value of the respondent's weight gain during pregnancy was $12.3 \mathrm{Kg}$ with a standard deviation of 1.6 and the lowest weight gain was 10 , while the highest body weight was $16 \mathrm{Kg}$. From the results of statistical tests with Product Moment Correlation, it was found that the $\mathrm{p}$ value $=0.000$ and the value $(r=0.506)$ was also obtained, this means that the increasing the mother's weight during pregnancy, the more the baby's weight will increase.
\end{abstract}

Keywords : Weight Gain, Pregnant Women, Newborns

\begin{abstract}
Abstrak
Telah dilakukan penelitian di Klinik bidan K.Saragih tahun 2019 yaitu untuk mengidentifikasi pengaruh peningkatan berat badan selama kehamilan terhadap berat badan bayi lahir. Desain penelitian yang digunakan adalah deskriptif kolerasi dengan besar sampel sebanyak 100 orang dengan metode pengambilan sampel secara total sampling. Instrumen dalam penelitian ini berupa data sekunder yang diperoleh dari data di Klinik bidan K.Saragih, KMS ibu hamil, catatan persalinan, dan berat badan bayi lahir. Dari hasil penelitian yang diperoleh nilai rata-rata kenaikan berat badan responden selama kehamilan yaitu $12,3 \mathrm{Kg}$ dengan standar deviasi yaitu 1,6 dan kenaikan berat badan terendah 10, sedangkan berat badan tertinggi $16 \mathrm{Kg}$. Dari hasil uji statistik dengan Korelasi Product Moment diperoleh nilai $p$ value $=0.000$ dan diperoleh juga nilai $(r=0,506)$ ini artinya semakin meningkat berat badan ibu selama kehamilan maka semakin meningkat pula berat badan bayinya.
\end{abstract}

Kata Kunci: Kenaikan Berat Badan, Ibu Hamil, Bayi Baru Lahir

\section{PENDAHULUAN}

Kehamilan merupakan permulaan suatu kehidupan baru suatu periode pertumbuhan. Kondisi kesehatan dimasa lampau sekaligus keadaan kesehatan ibu saat ini merupakan landasan suatu kehidupan baru. Nutrisi merupakan satu dari banyak faktor yang ikut mempengaruhi hasil akhir kehamilan. Ibu hamil dengan status gizi yang buruk perlu mendapat perawatan khusus. Ras dapat mempengaruhi hasil akhir kehamilan (Bobak et al. 2005).

Rata-rata pertambahan berat badan ibu hamil selama kehamilan berkisar $11,5 \mathrm{~kg}$, $25 \%$ untuk janin, selebihnya volume darah ibu yang meningkat, rahim dan jaringan kelenjar susu, cairan amnion dan plasenta. Oleh sebab itu, perlu dilakukan Ante natal care untuk mengikuti pertumbuhan dan perkembangan janin, sehingga wanita dan keluarga perlu melakukan persiapan tugas- 
tugas kehamilan (Tomy, 2008). Pertambahan berat badan yang dianjurkan bagi kehamilan yang normal adalah sekitar 10-15 $\mathrm{kg}$ (Macdougall, 2008).

Hasil survey Depkes RI pada tahun 1996 menunjukkan bahwa 41\% ibu hamil di indonesia menderita gizi buruk, dengan $51 \%$ menderita anemia. Keadaan ini membuat kecenderungan ibu melahirkan bayi dengan berat badan lahir rendah (BBLR) (Solihin, dkk 2005). Kenaikan berat badan ibu selama kehamilan berhubungan langsung dengan berat badan bayinya, dan risiko melahirkan BBLR meningkat dengan kurangnya kenaikkan berat badan selama kehamilan. Hal ini menunjukkan adanya hubungan yang signifikan antara Kenaikan berat badan ibu hamil dengan berat bayi lahir (Setianingrum et al, 2005)

Berdasarkan uraian di atas maka penulis tertarik untuk melakukan penelitian dengan judul Pengaruh Peningkatan Berat Badan Selama Kehamilan Terhadap Berat Badan Bayi di Klinik bidan K.Saragih Tahun 2019.

Penelitian ini bertujuan untuk mengidentifikasi pengaruh peningkatan berat badan selama kehamilan terhadap berat badan bayi lahir diKlinik bidan K.Saragih tahun 2019.

\section{METODE PENELITIAN}

Desain penelitian yang digunakan dalam penelitian ini adalah deskriptif Korelasi yaitu untuk mengetahui hubungan yang terjadi pada sebuah fenomena dengan mengidentifikasi hubungan yang terjadi antara variable (Suyanto dan Salamah, 2009). Sampel dalam penelitian ini adalah ibu-ibu yang bersalin dan bayi baru lahir di Klinik Bersalin bidan K.Saragih.Sampel yang diambil dalam penelitian ini adalah total sampling sebanyak 100 orang. Adapun kriteria sampel yang akan dipakai adalah: 1) Ibu hamil yang memeriksakan kehamilan di Klinik bidan K.Saragih, 2) Ibu yang melahirkan di Klinik bidan K.Saragih.

Instrumen penelitian adalah alat atau fasilitas yang digunakan oleh peneliti dalam mengumpulkan data agar pekerjaannya lebih mudah dan hasilnya lebih baik, dalam arti lebih cermat, lengkap, serta sistematis sehingga lebih mudah diolah (Arikunto, 2006). Instrumen penelitian ini adalah: data sekunder yang dikumpulkan dari data status pasien ibu post partum.

Hipotesa diuji dengan menggunakan teknik analisa korelasi product moment. Teknik analisis korelasi ini digunakan untuk mencari koefisien korelasi atau kekuatan hubungan. Taraf signifikan $(\alpha=0.05)$, pedoman dalam menerima hipotesis : jika nilai $\mathrm{P}<0.05$ maka $\mathrm{H}_{0}$ ditolak, apabila nilai $\mathrm{P}$ $>0,05$ maka $\mathrm{H}_{0}$ gagal ditolak. Data disajikan dalam bentuk tabel agar dapat dengan mudah melihat hubungan peningkatan berat badan selama kehamilan terhadap berat badan bayi baru lahir.

\section{HASIL}

\section{Analisa Univariat}

Analisa univariat ini bertujuan untuk melihat hubungan antara berat badan ibu selama kehamilan terhadap berat badan bayi baru lahir. Data yang bersifat kategorik yaitu usia, pendidikan dan pekerjaan, paritas, jarak kehamilan, kunjungan ANC. Data yang bersifat numerik dicari mean, median dan standar deviasinya.

Tabel 1. Distribusi Frekwensi Responden Berdasarkan Karakteristik Responden Ibu Hamil di Klinik Bidan K.Saragih.

\begin{tabular}{|c|c|c|}
\hline $\begin{array}{l}\text { Karakteristik } \\
\text { Responden }\end{array}$ & $\frac{\text { Frekuensi }}{n}$ & $\frac{\text { Persentase }}{\%}$ \\
\hline \multicolumn{3}{|l|}{ Umur } \\
\hline $20-25$ & 18 & 18 \\
\hline $26-30$ & 74 & 74 \\
\hline$>31$ & 8 & 8 \\
\hline Total & 100 & 100 \\
\hline \multicolumn{3}{|l|}{ Pendidikan } \\
\hline SD & 6 & 6 \\
\hline SMP & 21 & 21 \\
\hline SMA & 53 & 53 \\
\hline DIPLOMA & 17 & 17 \\
\hline SARJANA & 3 & 3 \\
\hline Total & 100 & 100 \\
\hline \multicolumn{3}{|l|}{ Pekerjaan } \\
\hline IRT & 80 & 80 \\
\hline PNS & 9 & 9 \\
\hline SWASTA & 11 & 11 \\
\hline
\end{tabular}




\begin{tabular}{|c|c|c|}
\hline Total & 100 & 100 \\
\hline \multicolumn{3}{|l|}{ Paritas } \\
\hline 1 anak & 9 & 9 \\
\hline 2 anak & 71 & 71 \\
\hline 3 anak & 17 & \\
\hline$>3$ anak & 3 & 17 \\
\hline Total & 100 & 100 \\
\hline \multicolumn{3}{|c|}{ Jarak Kehamilan } \\
\hline$<1$ Tahun & 2 & 2 \\
\hline 1 Tahun & 33 & 33 \\
\hline$>2$ Tahun & 65 & 65 \\
\hline Total & 100 & 100 \\
\hline \multicolumn{3}{|c|}{ Kunjungan ANC } \\
\hline $1 \mathrm{x}$ & - & - \\
\hline $2 \mathrm{x}$ & 6 & 6 \\
\hline $3 x$ & 20 & 20 \\
\hline $4 \mathrm{x}$ & 74 & 74 \\
\hline Total & 100 & 100 \\
\hline
\end{tabular}

Dari hasil uji statistik pada kenaikan berat badan responden selama kehamilan, dapat digambarkan dengan nilai mean = 12,37, dengan standar deviasi $=1,6$ dan kenaikan berat badan terendah $10 \mathrm{Kg}$. Dapat dilihat pada tabel 2 berikut ini:

\begin{tabular}{|c|c|c|c|c|}
\hline Tabel 2. & Dist & busi & Resp & onden \\
\hline Berdasarkan & Kena & an & Berat & Badan \\
\hline $\begin{array}{l}\text { Selama Kel } \\
\text { K.Saragih Ta }\end{array}$ & imilan & di & Klinik & bidan \\
\hline Variabel & Mean & SD & $\begin{array}{l}\text { Min - } \\
\text { Max }\end{array}$ & $\mathbf{N}$ \\
\hline Kenaikan & & & & \\
\hline Berat badan & 12,37 & 1,674 & $10-16$ & 100 \\
\hline Selama & & & & \\
\hline Kehamilan & & & & \\
\hline
\end{tabular}

Dari hasil uji statistik pada berat badan bayi baru lahir dapat digambarkan dengan nilai mean $=2966$, dengan standar deviasi $=287,17$ dan kenaikan berat badan terendah 2500 gr sedangkan berat badan tertinggi 4000 gr. Dapat dilihat pada tabel 3 berikut ini:

Tabel 3. Distribusi Responden Berdasarkan Berat Badan Bayi Baru Lahir Di Klinik bidan K.Saragih Tahun 2019

\begin{tabular}{lcclc}
\hline \multicolumn{1}{c}{ Variabel } & Mean & SD & $\begin{array}{l}\text { Min - } \\
\text { Max }\end{array}$ & N \\
\hline Berat badan & 2966 & 287,174 & $2500-$ & 100 \\
Bayi Baru Lahir & & & 4000 & \\
\hline
\end{tabular}

\section{Analisa Bivariat}

Analisa ini digunakan untuk menguji pengaruh peningkatan berat badan ibu selama kehamilan terhadap berat badan bayi baru lahir. Untuk uji korelasi dapat dilihat pada tabel dibawah ini.

Tabel 4. Pengaruh Peningkatan Berat Badan Selama Kehamilan Terhadap Berat Badan Bayi Baru Lahir di Klinik bidan K.Saragih Tahun 2019.

\begin{tabular}{lcc}
\hline \multicolumn{1}{c}{ Variabel } & R & Nilai P \\
\hline $\begin{array}{l}\text { Kenaikan berat badan } \\
\text { selama kehamilan terhadap } \\
\text { berat badan bayi baru lahir }\end{array}$ & 0,506 & 0,000 \\
\hline
\end{tabular}

\section{PEMBAHASAN}

Dari hasil uji statistik diperoleh data bahwa mayoritas responden adalah berumur 26-30 tahun sebanyak 74 orang (74\%). Berdasarkan tingkat pendidikan mayoritas responden berpendidikan SMA sebanyak 53 orang $(53 \%)$. Berdasarkan pekerjaan mayoritas responden adalah ibu rumah tangga sebanyak 80 orang (80\%). Berdasarkan paritas mayoritas responden memiliki 2 anak atau yaitu sebanyak 71 orang (71\%). Berdasarkan jarak kehamilannya mayoritas responden adalah jarak kehamilan $>2$ tahun yaitu sebanyak 65 orang $(65 \%)$. Sedangkan berdasarkan kunjungan ANC mayoritas responden adalah 4 kali memeriksakan kandungannya selama kehamilan yaitu sebanyak 74 orang (74\%).

Berdasarkan uji statistik hubungan antara variabel kenaikan berat badan selama kehamilan dengan berat badan bayi baru lahir diperoleh nilai $r=0,506$ yang berarti hubungan antar variabel ada korelasi yang cukup kuat, dengan arah positif. Maksudnya, jika salah satu variabel naik, maka variabel yang lain akan turun, atau jika variabel bebas memiliki nilai besar maka variabel tergantungnya menjadi kecil. Nilai $\mathrm{P}=0,000$ ini berarti ada hubungan yang signifikan.

\section{KESIMPULAN}

Berdasarkan hasil penelitian dan pembahasan tentang pengaruh peningkatan berat badan ibu selama kehamilan terhadap berat badan bayi baru lahir dapat disimpulkan sebagai berikut: 
1. Dari hasil uji statistik pada 100 responden berdasarkan kenaikan berat badan selama kehamilan, dapat digambarkan hasilnya yaitu nilai mean $=12,37$, dengan standar deviasi $=1,6$ dan kenaikan berat badan terendah $10 \mathrm{~kg}$ sedangkan berat badan tertinggi $16 \mathrm{Kg}$.

2. Dari hasil uji statistik pada 100 responden berdasarkan berat badan bayi baru lahir, dapat digambarkan hasilnya yaitu nilai mean $=2966$ dengan standar deviasi $=$ 287,17 dan kenaikan berat badan terendah 2500 gr sedangkan berat badan tertinggi 4000 gr.

3. Dari hasil uji statistik pada 100 responden diperoleh nilai $\mathrm{P}=0,000$ maka dapat disimpulkan ada hubungan yang signifikan antara kenaikan berat badan selama kehamilan dengan berat badan bayi. Nilai $r=0,506$ maka dapat disimpulkan ada hubungan yang cukup kuat, dengan arah positif, yang berarti jika salah satu variabel naik, maka variabel yang lain akan turun.

\section{SARAN}

Hasil penelitian ini dapat menjadi dasar untuk pengembangan ilmu keperawatan maternitas mengenai pengaruh peningkatan berat badan selama kehamilan terhadap berat badan bayi yang baru lahir.

\section{REFERENSI}

Arikunto., Suharsimi, (2006). Prosedur penelitian suatu pendekat praktik. Jakarta: Edisi revisi VI . PT. Rineka cipta.

Bobak, Irene M. dkk. (2005). Buku ajar keperawatan maternitas. Edisi 4. Jakarta: EGC.

Macdougall, Jane. (2008). Kehamilan minggu demi minggu. Jakarta : PT Gelora Aksara Pratama.

Setianingrum et al. (2005). "Hubungan Antara Kenaikan Berat Badan, Lingkar Lengan Atas, dan Kadar Hemoglobin Ibu Hamil Trimester III Dengan Berat Bayi Lahir di Puskesmas Ampei Boyolali Tahun 2005". Dikutip dari http://digilib.unnes.ac.id/gsdl/collect/ skripsi/archives/HASH018c/f2c7590 9.dir/doc.pdf. 27 Juni 2017.

Solihin, Pudjiadi. (2005). Ilmu gizi klinis pada anak. Jakarta: Balai Penerbit FKUI.

Suyanto \& Salamah, Ummi. (2009). Riset kebidanan metodologi \& aplikasi. Yogjakarta: Mitra Cendikia Press.

Tomy. (2008). "Studi Banding Kadar Hemoglobin Dan Tinggi Fundus Uteri Maternal Terhadap Luaran Berat Badan Lahir Normal Dan Rendah". Dikutip dari http://repository.usu.ac.id/bitstream/ 123456789/6457/1/08E00813.pdf.02 Oktober 2019. 